\title{
EVALUASI INVESTASI PROPERTI PADA PERUMAHAN BUMI KANJURUHAN (STUDI PADA PT. KHARISMA KARANGPLOSO)
}

\author{
Kalis Ayuk Widiastuti \\ Department of Management FEB UMM \\ E-mail: kalisdias@gmail.com
}

\begin{abstract}
Business Listing means issuing or investing in land or buildings plus, the benefits in the form of purchasing power protection against inflation and get the added value of its development, such as commercial or residential used. PT. Kharisma Karangploso build Housing Project Earth Kanjuruhan to meet the basic needs of society, especially civil servants to perform simple but decent housing development. This study aimed to determine the Evaluation of Development Project Feasibility Study Earth Kanjuruhan that in value in accordance with aspects of the Feasibility Study and also in accordance with the assessment of investment criteria. The result of this study indicate that the feasibility study of business is considered feasible and the result assesment of investment criteria at PP (Payback Periode) for 4 years 3 month 12 days, ARR (Average ate of Return) amount30,92\% > 6,148\%, the result of NPV (Net Pesent Value) is positive187.940.169, IRR (Internal Rate of Return) 8,6975\% > $6,148 \%$, and the last PI (Profitability Index) 1,449> 1.
\end{abstract}

Keywords : investment, business feasibility study, investment evaluation.

\section{PENDAHULUAN}

Pelaksanaan penelitian ekonomi dan studi khusus tentang permasalahan pembangunan, memberikan bantuan teknik untuk perencanaan investasi atau untuk setiap tugas pembangunan yang banyak. Pembangunan ekonomi sebagian besar bergantung pada langkah faktor-faktor nonekonomi seperti faktor-faktor sosial, budaya, dan kelembagaan serta politik. Sifatsifat politik yang dapat terjadi misalnya dalam alokasi sumberdaya diantara sektor-sektor dalam ukuran dan penentuan waktu penyesuaian harga-harga di sektor negara. Tetapi tidak mungkin melukiskan secara memadai tekanan politik yang secara konstan dihadapi para pejabat di negara-negara yang sedang berkembang.

Para pengembang properti, pengamat, dan konsultan properti menilai dari hasil Pusat Studi Properti Indonesia (PSPI) menyebutkan bahwa ada beberapa hal yang bisa membuat sektor properti bertumbuh pada 2016, hal ini terlihat bahwa tahun 2015 merupakan titik terendah dalam bisnis properti. Hal itu terlihat dari banyaknya developer yang tidak memenuhi target penjualan selama 
tahun tersebut. Miringnya industri properti digadang-gadang karena karena dampak melemahnya ekonomi nasional.

Hal inilah yang menjadi dasar bagi developer untuk mengembangkan bisnis properti ini. Semakin besarnya peluang bisnis di kota Kepanjen dan sekitarnya di lirik oleh para developer baik dari dalam daerah Kepanjen maupun luar daerah. Salah satu developer yang mengembangkan bisnis perumahan adalah PT. Kharisma Karang Ploso dengan proyek pembangunan perumahan Bumi Kepanjen yang berlokasi di Jalan Lingkar Barat Desa Ngadilangkung Kecamatan Kepanjen.

\section{TINJAUAN PUSTAKA}

Penelitian yang dilakukan oleh Putu Dharma Warsika (2009) tentang Studi Kelayakan Investasi Bisnis Properti (Studi Kasus : Ciater Riung Rangga). Penelitian ini dilakukan untuk mengetahui layak atau tidaknya investasi. Berdasarkan kriteria penilaian investasi dengan menggunakan analisa Net Cash Flow, NPV, IRR, ARR, PP dan $P I$.Hasil evaluasi kelayakan investasi tersebut layak.

Penelitian kedua dilakukan oleh Anton (2012) meneliti tentang Studi Kelayakan Investasi Properti Proyek Pembangunan Perumahan Citra Alam Mandiri Sukoharjo. Penelitian ini ditujukan untuk mengetahui apakah proyek pembangunan sesuai dengan perencanaan anggaran biaya, dan untuk mengetahui kelayakan investasi bila ditinjau dari finansial. Teknik analisis menggunakan NPV (net present value),IRR (internal rete of return) dan BCR (benefit cost ratio) dan hasil investasi tersebut layak untuk di jalankan.

Penelitian ketiga oleh Yunita (2015) meneliti tentang Studi Kelayakan Investasi Perumahan UME Melinan Permai Kabupaten Kupang. Parameter investasi ini adalah meninjau aspek keuangan dengan metode Net Present Value (NPV) dan Benefit Cost Ratio (BCR). Hasil penelitian tersebut di simpulkan layak.

Investasi menurut Martono dan Harjito (2010:138) merupakan penanaman dana yang dilakukan oleh suatu perusahaan ke dalam suatu aset (aktiva) dengan harapan memperoleh pendapatan dimasa yang akan datang. Dilihat dari jangka waktunya, investasi dibedakan menjadi investasi jangka panjang, investasi jangka menengah dan investasi jangka pendek.

Studi Kelayakan Bisnis menurut Suad Husnan (2000:4) merupakan penelitian tentang dapat tidaknya suatu proyek (biasanya merupakan proyek investasi) dilaksanakan dengan berhasil. Pengertian keberhasilan ini mungkin bisa ditafsirkan agak berbeda-beda. Ada yang menafsirkan dalam artian yang lebih terbatas, ada juga yang mengartikan dalam artian yang lebih luas. Artian yang lebih terbatas, terutama digunakan oleh pihak swasta yang lebih berminat tentang manfaat ekonomis suatu investasi. Aspek-aspek dalam Studi Kelayakan meliputi aspek pasar dan pemasaran, aspek teknis dan produksi, aspek organisasi dan manajemen, aspek ekonomi dan sosial, aspek keuangan.

Pihak-pihak yang memerlukan Studi Kelayakan Bisnis. Studi kelayakan bisnis sangat di perlukan 
bagi pihak-pihak tertentu dalam memulai kegiatan bisnisnya. Ada beberapa pihak yang sangat berkepentingan dengan dilakukannya studi kelayakan bisnis menurut Sucipto (2010:11) Investor akan mempelajari hasil studi kelayakan bisnis yang telah di buat sebelum menanamkan modalnya pada bisnis yang dikehendaki. Kreditur terlebih dahulu mengkaji hasil studi kelayakan bisnis tersebut sebelum mengucurkan kredit. Penyusunan studi kelayakan bisnis perlu memperhatikan kebijakan-kebijakan pemerintah kebijakan-kebijakan pemerintah tersebut mempengaruhi kebijakan perusahaan.

\section{KERANGKA PIKIR}

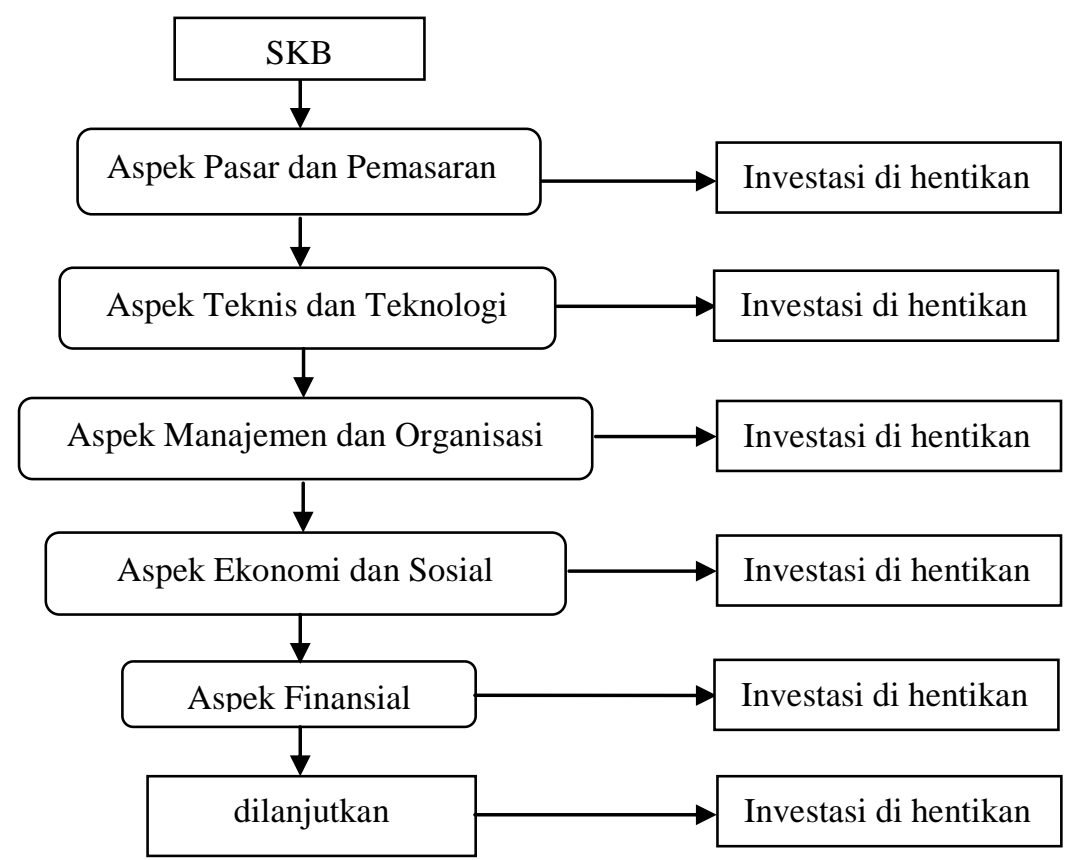

Gambar 1. Kerangka Pikir

\section{METODE PENELITIAN}

Lokasi Penelitian dilakukan pada proyek Perumahan Bumi Kanjuruhan di Jalan Lingkar Barat Desa Ngadilangkung Kecamatan Kepanjen, Malang- Jawa Timur. Jenis penelitian ini menggunakan studi kasus atau penelitian kasus. Penelitian kasus merupakan studi mendalam mengenai unit sosial tertentu, yang hasil penelitian itu memberi gambaran luas dan mendalam mengenai unit sosial tertentu.

Definisi Operasional variabel meliputi Investasi, Studi Kelayakan
Bisnis dan Aspek-aspek dalam Studi Kelayakan Bisnis meliputi aspek pasar dan pemasaran, aspek teknis dan produksi, aspek organisasi dan manajemen, aspek ekonomi dan sosial, aspek keuangan.

Jenis dan Sumber Data yang digunakan adalah penelitian diskriptif dan sumber data meliputi sumber data primer dan sekunder. Teknik pengumpulan datayang dilakukan peneliti yaitu dengan melakukan wawancara dan juga dokumentasi. Teknik analisis datayang di lakukan oleh peneliti meliputi dua hal, antara lain: 
Menggambarkan penerapan SKB (Studi Kelayakan Bisnis yang dilakukan oleh PT Kharisma Karang Ploso dan Studi Kelayakan Bisnis (SKB) yang sesuai dengan aspekaspek SKB dan kriteria penilaian investasi : Aspek Pasar dan Pemasaran dengan menetapkan pangsa pasar, analisa pesaing, potensi pasar dan saya beli, pemasaran dengan menentukan strategi pemasaran.

Aspek teknis dan produksi menjabarkan kegiatan teknis meliputi alat dan teknologi yang digunakan, dan menguraikan bahan baku, aspek organisasi dan manajemen memperinci semua pekerjaan yang harus dilakukan untuk mencapai tujuan, pihak-pihak yang terlibat dalam proses pembangunan yang didalamnya meliputi pembagian kerja, menyusun mekanisme untuk mengkoordinir pekerjaan dari para anggota organisasi ke dalam satuan yang terpadu, serta penggajian termasuk insentif pekerja dalam kegiatan pembangunan, aspek ekonomi dan sosial melihat adanya dampak dari kegiatan investasi akan mengakibatkan dampak positif dan negatif, aspek terakhir merupakan aspek keuangan dengan menghitung kriteria penilaian investasi :

Investasi awal

Investasi awal $=($ harga beli aktiva + biaya-biaya investasi) - (proceeds dari penjualan aktiva tetap yang sama \pm pajak atas penjualan aktiva)

Biaya Modal (CoC)

Biaya modal ada dua yaitu modal asing dan sendiri. Untuk menghitung modal asing maka formulanya

$$
K_{d}=\frac{\text { BebanHutang }}{\text { HutangJangkaPanjang }}
$$

menghitung biaya utang setelah pajak :

$$
\mathrm{Ki}=\mathrm{Kd}(1-\mathrm{T})
$$

Untuk menghitung modal sendiri maka Biaya Hutang ditambahkan dengan Premi Resiko. Untuk menghitung Aliran Kas Bersih $(N C F)$ maka dapat digunakan formula sebagai berikut:

$$
\begin{gathered}
N C F t=E A T+\text { Depresiasi }+ \text { Bunga } \\
(1-\text { Pajak }) \\
N C F n=N C F t+T C F
\end{gathered}
$$

Untuk menilai investasi dapat dihitung menggunakan beberapa metode. Pertama, metode Payback Period (PP), dengan rumus sebagai berikut:

$$
\begin{gathered}
P P=\text { Investasi awal }-\left(N C F_{1}+N C F_{2}\right. \\
\left.+N C F_{n}\right)
\end{gathered}
$$

Dengan kriteria, PP > umur ekonomis, maka proyek tidak layak dilaksanakan, $\mathrm{PP} \leq$ umur ekonomis, maka proyek layak dilaksanakan

Metode Average Rate of Return ARR. Perhitungan Average Rate of Return (ARR) dilakukan sebagai berikut:

$$
A R R=\frac{\text { AverageEarningAfterTax }}{\text { AverageInvestment }} \times 100 \%
$$

Dengan kriteria, ARR $\geq$ Cost of Capital (CoC), proyeklayak dilaksanakan. ARR < Cost of Capital $(\mathrm{CoC})$, proyektidak layak untuk dilaksanakan.

\section{Metode Net Present Value} (NPV). Perhitungan (NPV) dilakukan sebagai berikut:

$$
N P V=b+\frac{N C F 1}{(1+r)}+\frac{N C F 2}{(1+r)^{2}}+\cdots+\frac{N C F n}{(1+r)^{n}}
$$

Kriteria keputusan, NPV > 0 maka proyek layak dilaksanakan, NPV $\leq 0$ 
maka proyek tidak layak dilaksanakan

Metode Internal Rate of Return (IRR). Perhitungan Internal Rate of Return(IRR) dilakukan sebagai berikut:

$$
I R R=i_{1}+\frac{N P V_{1}}{N P V_{1}-N P V_{2}} x\left(i_{2}-i_{1}\right)
$$

Kriteria keputusan, IRR $\geq \mathrm{CoC}$, maka proyek layak dilaksanakan

IRR < CoC, maka proyek tidak layak dilaksanakan.

Profitability Index (PI).

Perhitungan Profitability Index

(PI)dilakukan sebagai berikut:

$$
\mathrm{PI}=\frac{\sum \text { NetCashFlow }}{\text { InvestasiAwal }}
$$

Dengan kriteria, PI > 1 , maka proyek layak dilaksanakan. $\mathrm{PI} \leq 1$, maka proyek tidak layak untuk dilaksanakan

\section{HASIL DAN PEMBAHASAN}

Aspek Pasar dan Pemasaran, pada aspek pasar menentukan lokasi pasar pada proyek pembangunan Perumahan Bumi Kanjuruhan terletak di Jalan Lingkar Barat Desa Ngadilangkung

Kecamatan Kepanjen - Malang. Melakukan analisa pesaing

Tabel 1. Harga Perumahan PNS Pesaing

\begin{tabular}{clccc}
\hline No & \multicolumn{1}{c}{ Nama Perumahan } & Type & Unit & Harga \\
\hline 1 & Perumahan Lesanpuro & 32 & 240 & Rp 90.000.000 \\
2 & Perumahan Grand Khalifah & 36 & 300 & Rp 275.000.000 \\
3 & Perumahan Karangduren & 36 & 100 & Rp 150.000.000 \\
4 & Perumahan Indence Cluster & 36 & 200 & Rp 200.000.000 \\
5 & Perumahan Bumi Kanjuruhan & 36 & 371 & Rp 98.495.000 \\
\hline
\end{tabular}

Meninjau potensi pasar dilihat dari data pertumbuhan PNS di Kabupaten Malang yang setiap tahun mengalami peningkatan. Permintaan produk perumahan PNS dapat diketahui dari tingkat hunian (occupancy) dari kawasan perumahan PNS lain yang telah ada. Berdasarkan hasil pengamatan, permintaan masyarakat khususnya PNS cukup tinggi. Daya Beli PNS terhadap Perumahan Bumi Kanjuruhan didukung dengan besarnya pendapatan yang di dapat. Pendapatan PNS aktif dari golongan I hingga golongan IV yang dapat memenuhi persyaratan pembelian merupakan PNS yang memiiki gaji dibawah 4 juta.

Aspek Pemasaran yang dilakukan yaitu dengan melakukan kegiatan sosialisasi, pembuatan pamflet, dan juga pembuatan brosur. Aspek Teknis merinci semua alatalat dan teknologi yang diguanakan dalam kegiatan proses pembangunan Perumahan Bumi Kanjuruhan.

Aspek Produksimemberikan semua rincian bahan baku yang digunakan dalam kegiatan pembangunan Perumahan Bumi Kanjuruhan. Aspek Organisasi pada proyek Perumahan Bumi Kanjuruhan memiliki total tukang dan pekerja sebanyak 30 orang. Masing- masing dari setiap pekerja memiliki tugas yang telah ditetapkan.

Hal ini dilakukan agar memudahkan dalam bekerja, serta meningkatkan efisien dan keefektifan dalam bekerja. Aspek Manajemen meliputi bagian lapangan yang 
bertanggung jawab adalah Dwi Purbo sedangkan pada bagian pengawas, kedua penanggung jawab proyek tersebut diambil langsung dari pihak intern PT. Kharisma Karang Ploso.

Aspek manajemen juga memperlihatkan biaya tenaga kerja yang di butuhkan untuk membayar seluruh pekerja yang terlibat pada proses pembangunan Bumi Kanjuruhan. Aspek Ekonomi dan
Sosial, dampak ekonomi meliputi dapat meningkatkan ekonomi rumah tangga, menggali, mengatur, dan menggunakan meningkatkan ekonomi, pmerintah, pengembangan wilayah, eksplorasi sumberdaya yang berlebihan. Dampak sosial meliputi Komponen Demografi, Komponen Budaya, Kesehatan masyarakat, Meningkatnya kriminalitas. Aspek Keuangan meliputi :

Tabel 2. Investasi Awal (Dalam Rupiah)

\begin{tabular}{llll}
\hline Modal Kerja & \multicolumn{3}{c}{ Pasiva } \\
\hline Kas & 2.000 .000 .000 & Hutang Usaha & 3.000 .000 .000 \\
Piutang & 127.375 .000 & Modal & \\
Persediaan & 478.587 .775 & Modal Sendiri & $\mathbf{2 . 0 0 0 . 0 0 0 . 0 0 0}$ \\
& & & \\
Aktiva & & & \\
Tanah & 2.363 .270 .000 & & \\
Alat & 7.008 .225 & & \\
Pemasaran & 22.260 .000 & & $\mathbf{5 . 0 0 0 . 0 0 0 . 0 0 0}$ \\
Perijinan & 1.500 .000 & & \\
Total Kebutuhan Investasi & $\mathbf{5 . 0 0 0 . 0 0 0 . 0 0 0}$ & & \\
\hline
\end{tabular}

Investasi awal terdiri dari kas sebesar Rp 2.000.000.000, piutang sebesar $\mathrm{Rp}$ 127.375.000 ini diperoleh dari pesanan konsumen ditahun pertama sebanyak 25 unit dengan uang muka yang diberikan. Persediaan sebesar Rp 478.587.775. Biaya pembebasan tanah sebesar Rp 2.363.270.000 untuk keseluruhan tanah seluas 6,9 hektar. Biaya untuk pembelian alat sebesar Rp 7.008.225. Biaya pemasaran pada tahun pertama sebesar Rp 22.260.000.
Biaya perijinan untuk 2 unit rumah sebesar Rp 1.500.000. Persediaan 5 unit rumah. Investasi awal yang dikeluarkan sebesar $\mathrm{Rp}$ 5.000.000.000 yang terdiri dari hutang usaha sebesar Rp 3.000.000.000 dan modal sendiri yang dikeluarkan oleh perusahaan sebesar Rp 2.000.000.000. Investasi awal digunakan untuk pembangunan rumah sebagai contoh produk di awal pembangunan.

Tabel 3. Sumber Modal (dalam Rupiah)

\begin{tabular}{lll}
\hline No & Sumber Dana & Nominal \\
\hline 1 & Modal Sendiri & \multicolumn{2}{c}{2.000 .000 .000} \\
2 & Modal Hutang & 3.000 .000 .000 \\
\hline \multicolumn{2}{l}{ Total Modal } & 5.000 .000 .000 \\
\hline
\end{tabular}


Sumber modal yang diperoleh dari perusahaan bersumber dari modal hutang dan juga modal sendiri. Modal hutang sebesar Rp 2.000.000.000 dan modal yang bersumber dari modal hutang sebesar Rp 3.000.000.000, sehingga total modal keseluruhan sebesar $\mathrm{Rp}$ 5.000.000.0000.

Tabel 4. NCF (Dalam Rupiah)

\begin{tabular}{cccccc}
\hline Th & EAT & Depresiasi & Bunga (1-T) & TCF & NCF \\
\hline 1 & -313.557 .500 & 50.436 .500 & 29.700 .000 & - & -233.421 .000 \\
2 & 91.488 .900 & 50.436 .500 & 29.700 .000 & - & 171.625 .400 \\
3 & 256.039 .000 & 50.436 .500 & 29.700 .000 & - & 336.175 .500 \\
4 & 509.193 .000 & 50.436 .500 & 29.700 .000 & - & 589.329 .500 \\
5 & 1.002 .843 .300 & 50.436 .500 & 29.700 .000 & 952.428 .500 & 2.035 .408 .300 \\
\hline Total & 1.546 .006 .700 & & & 2.899 .117 .700 \\
\hline
\end{tabular}

Tabel 5. Payback Periode (Dalam Rupiah)

\begin{tabular}{lrr}
\hline Th & \multicolumn{1}{c}{ NCF } & \\
\hline & & Kumulatif \\
1 & -233.421 .000 & 2.000 .000 .000 \\
2 & 171.625 .400 & 1.766 .579 .000 \\
3 & 336.175 .500 & 1.594 .953 .600 \\
4 & 589.329 .500 & 1.258 .778 .100 \\
5 & 2.035 .408 .300 & 669.448 .600 \\
\hline Total & 2.899 .117 .700 & \\
\hline
\end{tabular}

Berdasarkan hasil perhitungan dihasilkan 4 tahun 3 bulan 12 hari $\mathrm{PP}<5 \mathrm{Th}$, maka proyek dinyatakan layak.

$$
\begin{aligned}
& A R R=\frac{1.546 .006 .700}{5}=309.201 .340 \\
& A I=\frac{2.000 .000 .000}{2}=1.000 .000 .000
\end{aligned}
$$

sehingga

$$
\begin{aligned}
A R R= & \frac{\text { AverageEarningAfterTax }}{\text { AverageInvestmen }} \times 100 \% \\
& =\frac{309.201 .340}{1.000 .000 .000} \times 100 \% \\
& =0,3092 \times 100 \% \\
& =30,92 \%
\end{aligned}
$$

ARR $\geq$ Cost Of Capital yang di isyaratkan $30,92 \%<6,148 \%$ Sehingga Proyek Layak untuk dilanjutkan.

Tabel 6. NPV (Dalam Rupiah)

\begin{tabular}{cccc}
\hline No & NCF & $6,148 \%$ & PV \\
\hline 1 & -233.421 .000 & 0,9420 & -219.882 .582 \\
2 & 171.625 .400 & 0,8875 & 152.317 .542 \\
3 & 336.175 .500 & 0,8361 & 281.076 .336 \\
4 & 589.329 .500 & 0,7876 & 464.155 .914 \\
5 & 2.035 .408 .300 & 0,7420 & 1.510 .272 .959 \\
\hline Total & & & 2.187 .940 .169 \\
Investasi & & & 2.000 .000 .000 \\
NPV & & & 187.940 .169 \\
\hline
\end{tabular}


Nilai NPV dihasilkan nilai positif sebesar 187.940.169> 0 , maka proyek layak untuk di
lanjutkan.Internal Rate of Return (IRR)

Tabel 7. IRR (Dalam Rupiah)

\begin{tabular}{|c|c|c|c|c|c|}
\hline $\mathrm{Th}$ & $\mathrm{NCF}$ & $\mathrm{DF}(8 \%)$ & PVCF & $\mathrm{DF}(9 \%)$ & PVIF \\
\hline 1 & -233.421 .000 & 0,9259 & -216.124 .503 & 0,9174 & -214.140 .425 \\
\hline 2 & 171.625 .400 & 0,8573 & 147.134 .455 & 0,8416 & 144.439 .937 \\
\hline 3 & 336.175 .500 & 0,7938 & 266.856 .112 & 0,7721 & 259.561 .103 \\
\hline 4 & 589.329 .500 & 0,7350 & 433.157 .183 & 0,7084 & 417.481 .018 \\
\hline 5 & 2.035.408.300 & 0,6805 & 1.385 .095 .348 & 0,6499 & 1.322 .811 .854 \\
\hline \multirow{2}{*}{\multicolumn{2}{|c|}{ Total Kas Bersih }} & & 2.016.118.594 & & 1.930 .153 .487 \\
\hline & & & 2.000 .000 .000 & & 2.000 .000 .000 \\
\hline \multirow{2}{*}{\multicolumn{2}{|c|}{ NPV }} & NPV1 & 161.118 .595 & NPV2 & -69.846 .513 \\
\hline & & I1 & $8 \%$ & $\mathrm{I} 2$ & $9 \%$ \\
\hline
\end{tabular}

Diketahui : NPV1 : 161.118 .595

NPV2 : -69.846 .513$

I1 : $8 \%$

I2: $: 9 \%$

Sehingga IRR

$=I 1+\frac{N P V 1}{N P V 1-N P V 2} x(I 2-I 1)$

$=8 \%+\frac{161.118 .595}{161.118 .595-(-69.846 .513)} x$

$=8+0,6975 \%$

$=8,6975 \%$

Hasil dari IRR sebesar 8,6975\%, sehingga $8,6975 \%>6,148 \%$ maka proyek layak dan dapat di lanjutkan.

Probability Index (PI) :

$P I=\frac{\sum \text { NetCashFlow }}{\text { InvestasiAwal }}$

$=\frac{2.899 .117 .700}{2.000 .000 .000}$

$=1,449$

=1,449> 1, maka Proyek Layak untuk dilanjutkan.

\section{PEMBAHASAN}

Berdasarkan hasil penelitian dan analisis yang dilakukan oleh peneliti pada Proyek Pembangunan Perumahan Bumi Kanjuruhan melakukan evaluasi investasi dengan melihat Studi Kelayakan Bisnis yang di lihat dari lima aspek yang meliputi aspek pasar dan pemasaran, aspek teknis dan produksi, aspek organisasi dan manajemen, aspek sosial ekonomi dan yang terakhir aspek finansial atau keuangan.

Hasil survey dan observasi yang telah dilakukan pada Proyek Perumahan Bumi Kanjuruhan, maka dari kelima aspek dinyatakan layak dan sesuai dengan penilaian kriteria investasi. Hasil pada aspek keuangan dihasilkan Payback Periode selama 4 tahun 3 bulan 12 hari, sehingga hasil ini kurang dari umur ekonomis selama 5 tahun, maka PP dinyatakan layak. Hasil dari ARR sebesar 30,92 $\%<6,148 \%$ sehingga proyek dinyatakan layak. Hasil dari NPV sebesar 187.940.169> 0 maka proyek dinyatakan layak, hasil dari IRR sebesar 8,6975 \%, sehingga 8,6975 $\%>6,148 \%$ maka proyek layak, dan yang terakhir Probability Index (PI) dihasilkan 1,449> 1, maka Proyek Layak untuk dilanjutkan.

\section{KESIMPULAN}

Berdasarkan hasil penelitian dan analisis yang dilakukan oleh peneliti, diketahui permasalahan yang dihadapi oleh PT. Kharisma Karang Ploso dalam pembangunan Proyek Perumahan Bumi Kanjuruhan saat ini 
yaitu adanya perbedaan antara studi kelayakan bisnis yang dilakukan oleh PT. Kharisma Karang Ploso dengan studi kelayakan bisnis yang sesuai dengan penilaian kriteria investasi. Perbedaan ini menjadi evaluasi untuk investasi Perumahan Bumi Kanjuruhan.

Penelitian pada Proyek Perumahan Bumi Kanjuruhan yang meliputi lima aspek dalam pengevaluasiannya maka dapat disimpulkan bahwa Aspek Pasar dan Pemasaran, Aspek Teknis dan Produksi, Aspek Organisasi dan Manajemen, Aspek Ekonomi dan Sosial serta Aspek Finansial / keuangan dikatakan Layak sesuai dengan aspek-aspek studi kelayakan bisnis dan sesuai dengan kriteria penilaian investasi.

Berdasarkan analisis dan pembahasan diatas ada beberapa hal yang dapat disarankan yang didasarkan pada kegunaan penelitian yakni :Saran Bagi PT.Kharisma Karang Ploso, diharapkan sebaiknya PT.Kharisma Karang Ploso membuat dan merancang Studi Kelayakan Bisnis pada setiap proyek yang akan dijalankan termasuk pada Proyek Pembangunan Bumi Kanjuruhan. Bagi Kreditur, diharapkan meninjau studi kelayakan bisnis terlebih dahulu agar dapat menentukan keputusan yang baik dan bermanfaat bagi investasinya.

Bagi Peneliti Selanjutnya, Peneliti yang akan melakukan penelitian selanjutnya, disarankan untuk melihat dan meng update tingkat suku bunga yang berjalan dan berubah setiap tahunnya. Bagi peneliti lain juga diharapkan meninjau ulang harga bahan baku, harga sewa teknologi (alat berat), dan harga alat-alat karena setiap tahun dapat mengalami perubahan.

\section{DAFTAR PUSTAKA}

Abadi, Anton. 2012. "Studi Kelayakan Investasi Properti Proyek Pembangunan Perumahan Citra Alam Mandiri Sukoharjo". Surakarta Arikunto, dkk. 2008. Evaluasi Program Pendidikan. Jakarta: PT. Bumi Aksara

Beritasatu. 2016. Faktor-faktor Pemicu Pertumbuhan Properti. http://www.beritasatu.com/foru m-bisnis/346133-inilahfaktorfaktor-pemicupertumbuhan-properti2016.html.(di akses pada tanggal 28 oktober 2016.

BKD, 2016. Badan Kepegawaian Kota Malang, Data PNS Kota Malang. 2016.

Djaali, Punaji. 2008. Pengukuran Bidang Pendidikan. Jakarta : Grasindo

Echols dan Hassan Sadily. 2000. Kamus Inggris-Indonesia. Jakarta : Gramedia Pustaka Utama.

Fahmi, I. (2014) Analisis Laporan Keuangan. Bandung :Alfabeta

Herlianto, D, Pujiastuti T. 2009.

Studi Kelayakan Bisnis. Yogyakarta : Grata Ilmu

Husnan, Suwarsono. 2000. Studi Kelayakan Proyek. Edisi cetakan ke Empat. Yogyakarta.UPP AMP YKPN

Jakfar dan kasmir. 2012. Studi Kelayakan Bisnis Edisi 8. Jakarta : Kencana

Kompas. 2016. Puncak Pertumbuhan Properti Tahun 2016. http://properti.kompas.com/rea d/2014/12/11/130025921/Punc 
ak.Pertumbuhan.Properti.Terja

di.Tahun.2016.

(diaksespadatanggal 28

Oktober 2016)

Kuswadi. 2007. Analisa Perekonomian Proyek.

Yogyakarta : Penerbit Andi

Martono dan Harjito, 2005,

Manajemen Keuangan, Edisi

Pertama, Cetakan Kedua,

Yogyakarta :Ekonisia

Mayun, Nadiasa. 2011. "Evaluasi Investasi Pembangunan Taman Safari Di Gianyar" Jurnal Ilmiah teknik sipil, Vol 15 No.1 Januari

Mulyadi. 2010. Akuntansi Manajemen : Konsep, Manfaat dan Rekayasa. Yogyakarta : STIE YKPN

Murdifin, Salim. 2003. Studi Kelayakan Investasi. Edisi Cetakan 1. Jakarta. PPM

Punaji, Setyosari. 2010. Metode Penelitian Pendidikan dan Pengembangan. Jakarta. Kencana
Putu, Warsika. 2009. "Studi Kelayakan Investasi Bisnis Properti (Studi Pada Ciater Riung Rangga". Denpasar

Sucipto. 2010. Studi Kelayakan Bisnis Analisis Integratif dan Studi Kasus. Malang : UIN MALIKI PRESS

Sugiyono. 2012. Metode Penelitian Bisnis. Bandung : Alfabeta

Sutrisno. 2009. Manajemen Keuangan, Teori, Konsep dan Aplikasi. Yogyakarta : Ekonesia.

Undang-Undang Dasar.2016. Peraturan Pemerintah Republik Indonesia No 18 th 2008.http://pemerintahan.mala ngkota.go.id/wpcontent/upload s/sites/7/2016/08/ILPPD-20151.pdf. (diakses pada tanggal 15 januari 2017)

Yunita, Messah. 2015. "Studi Kelayakan Finansial Investasi Perumahan UME Malinan Permai Kabupaten Kupang". Kupang 